\title{
Admission Exam Web Application Prototype for Blind People at the University of Sciences and Humanities
}

\author{
Alexis Carrion-Silva ${ }^{1}$, Carlos Diaz-Nuñez ${ }^{2}$, Laberiano Andrade-Arenas ${ }^{3}$ \\ Faculty of Science and Engineering \\ Universidad de Ciencias y Humanidades, Lima Perú
}

\begin{abstract}
Currently, there is a large sector of Peru's population that has some type of disability. Every year, the government creates norms for their integration into society. However, to date, total integration is not achieved. One of the points that can be seen is at the moment of taking an entrance exam, where to this day, they do not have the tools to perform in an autonomous and optimal way. Taking this into account, the objective of this article is the development of a prototype admission test for blind people at the University of Sciences and Humanities. A hybrid methodology is used with between Soft Systems and Scrum. The results were obtained from the analysis of both methodologies and a final product prototyped with Balsamiq, demonstrating an optimal union between these two methodologies. Therefore, the prototype will facilitate the performance of blind people during their entrance exam.
\end{abstract}

Keywords-Admission; Balsamiq; blind; scrum; soft systems

\section{INTRODUCTION}

The entrance exam is one of the fundamental requirements for the entrance of students to universities today, although it is true that some universities have more rigorous entrance exams than others, specifically public universities. Today, many of these universities do not have admission test modalities for the visually impaired or tools that allow them to perform optimally when taking the admission test.

There are currently 39 million visually impaired people worldwide, representing $13 \%$ of the world's population [1]. Consequently, the technological evolution aimed at people with visual impairment has grown considerably, largely due to their difficulties. Today there are a great number of technological resources that guide people with visual impairment in their tasks, improving their autonomy in various aspects.

Online dating applications, is an example that nowadays has become a very common way to meet people. However, in most online dating platforms, most of the data is visual [2]. This creates an access barrier for people with visual impairments and prevents them from being able to fully use this tool or any type of online platforms.

In Peru, the National Institute of Statistics and Information (INEI) reported that 801,000 people are permanently limited in their ability to see, even when using glasses. Moreover, $52.6 \%$ are in urban areas and $44.8 \%$ in rural areas [3]. However, this number has not yet been fully included in many aspects of society, especially in university education, since tests for them are not yet well implemented. For example, the representatives in Puno noticed the absence of staff in charge of reading the questions to blind applicants [4]. He made it clear that even if they take the exams physically, they are still affected and do not have a better chance of taking the exam.

The inclusion in the applications should be guided in a participatory and collaborative act. Human action must be guided by dialogue between differences; the perspective of social-digital inclusion demands a change in the technological profile that must be a goal [5]. Under this concept of inclusion, the creation of a prototype application was thought of, which would make it possible to answer an online test in a simpler way for a blind person. This will allow a great step towards inclusion and will help to have greater chances of success in it.

The objective of this article is to develop a web prototype so that blind applicants can take an admission exam at the University of Sciences and Humanities with greater autonomy. In this way, a great step towards inclusion for the visually impaired will be taken.

The article is divided into sections, where Section II details the methodology to be implemented; Section III the application of the case study; Section IV the results and discussions obtained and Section $\mathrm{V}$ the conclusions and future work.

\section{METHODOLOGY}

For the elaboration of the web prototype, a hybrid methodology will be used, implementing stages 1 and 2 of the soft systems methodologies in order to identify in depth the problem to be addressed. Similarly, the scrum methodology was applied in order to manage the development of the project in an agile way.

\section{A. Soft Systems Methodology}

This methodology is based on the systemic thinking, where it allows to see under a holistic look, the integration of all the parts as a whole; the first and second stage of this methodology were taken into account: the unstructured and structured situation respectively. In this way, it is possible to analyze the behavior of the problem under study [6]. 


\section{B. Scrum Methodology}

The Scrum methodology is a framework for agile development, which facilitates the control and management of software development. It is an iterative and incremental model for the development of software [7]. As we can see in Fig. 1, it shows an example of the Scrum work cycle.

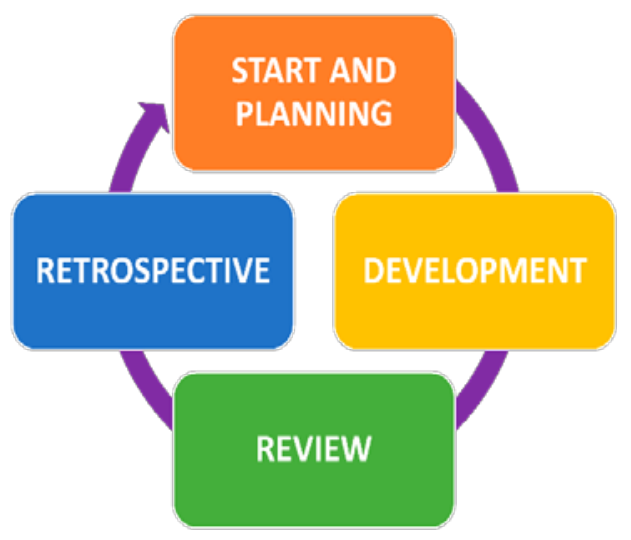

Fig. 1. Scrum Work Cycle.

\section{Scrum Methodology}

This hybrid methodology consists of 6 steps: unstructured stage, structured stage, initiation and planning, development, review and retrospective of the sprint.

1) Unstructured stage: The main causes found in the research problem are described, the central problem being the application of university entrance exams.

2) Structured stage: In this part, all those involved in the problem are described with graphics, interrelating each of them with the application of admission tests to blind people.

3) Initiation and planning of the sprint: The elaboration of the sprints can be considered as mini projects within the whole project. Within the first meeting, the team defines all aspects of its functionality, its objectives, risks, delivery times, among others. Later, meetings are scheduled between the Product Owner and the development team to detail how each point of the sprint will be developed. Changes are evaluated; decisions are made and improvements are made within the sprint [8].

4) Development of sprint: When the sprint is underway, the development team must ensure that the deadlines set in the development of the sprint are met. Similarly, the scope may be renegotiated between the development team and the product owner [8].

5) Sprint review: This is done at the end of each Sprint to check progress and adjust if necessary. Within the review, topics such as: verification of the software by owner, estimated completion dates according to the progress, a timeline review, among others, are seen [7].

6) Retrospective of the sprint: Here, the whole team makes an inspection of itself and a plan of improvements is elaborated to be able to execute them in the next Sprint. They review how they did during the sprint, identify and sort out what went well or badly, and implement the improvement plan to improve the team [7].

\section{Development Tools}

This section presents the tools that were used for the development of the web, which are the Apache server, the MySQL database manager and the PHP programming language.

1) Sublime text: Sublime Text, being a text and source code editor, will allow us to develop the web application, in the language of PHP and the revision of queries.

2) $P H P$ : $\mathrm{PHP}$ is an open source programming language natively focused on web development; its application goes hand in hand with HTML. This programming language has a syntax similar to the $\mathrm{C}$ language, java and Perl being one of the easiest programming languages to learn [9].

3) Apache: Apache HTTP Server is a free, open source web server software for Unix platforms that runs most websites worldwide. It is maintained and developed by the Apache Software Foundation.

4) MySQL: MySQL is a server and database manager; its architecture makes it a multiplatform tool. MSQL also offers flexibility when working in demanding environments such as web applications. In turn, MySQL can process data in embedded applications, data storage among others, as well as in redundant systems of high availability of online transaction processing (OLTP) [10].

\section{E. Tools for Prototyping}

Balsamiq and Adobe XD will be used for the elaboration of the application prototypes.

1) Adobe $X D$ : This tool will design the screens or GUI of the web application. Adobe XD is a tool that provides what is needed to design and prototype websites, mobile applications, voice interactions, touch screens and other types of user interactions [11].

2) Balsamiq: Balsamiq Mockups, is a tool for the creation of mockups, it facilitates the creation of the necessary design sketches in the software development process characterized by the tools it has, UI elements library, work area, navigation panel among others [12].

\section{CASE STUDY}

In this section, the six steps of the hybrid methodology for the problem will be developed.

\section{A. Unstructured Stage}

This section describes the main causes found in the research problem.

The first point is that there is little access to technology for blind people because, despite the fact that in Peru there are more than 1.5 million people who are blind or visually impaired, there are still not enough tools for them to use [13]. This can be seen in the admission exams, where not all universities have the tools to allow blind people to have a certain amount of autonomy when taking the exam.

The second point is the education law, which, despite establishing that it is a fundamental right of society (Article 3) 
and that the right to an inclusive education is recognized for all persons with a disability without discrimination (Article 21) [14], in addition, the process of admission to universities in Peru includes persons with a disability, as mentioned in the New University Law [14]. In addition, the admission process to universities in Peru includes persons with disabilities, as mentioned in the New University Law No. 30220 in Article 98: "Persons with disabilities are entitled to a reservation of 5 percent of the vacancies offered in their admission procedures (sic) [15]. In the same way, it was detected that the tests for blind applicants did not arrive on time to the classrooms where the exam was given.

The third point is the inequality that exists today in Peru, not only in education but in many areas of society. Despite the years the state has not been able to close this gap that would allow it to open the way to the inclusion of all citizens, despite its efforts and laws that were created so that this inequality does not exist to date, there are disabling barriers that still exist in society despite the laws and agreements to make a more inclusive world where everyone can feel welcome and accepted [16].

\section{B. Structured Stage}

As can be seen in Fig. 2, all those involved in the application of the entrance examinations can be seen; in addition, the interaction between the main parties involved, interpersonal relations and community participation can be seen [17].

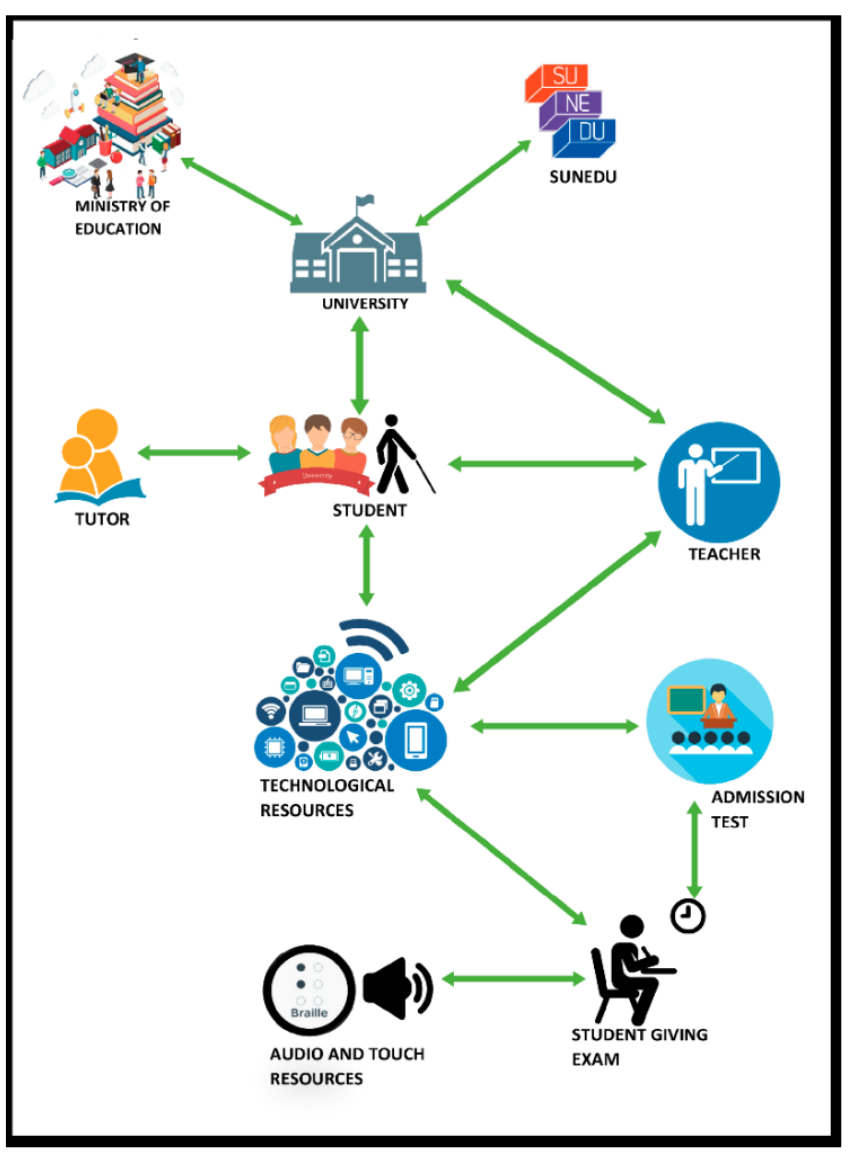

Fig. 2. Structured Situation.

\section{Planning and Estimation of user Stories}

Table I shows the prioritized user stories, previously estimated using the Delphi estimation group technique; the key words for the stories are "like", "want" and "for".

Having the user stories, we estimated and established Table II of the duration of each Sprint.

\section{Development of Sprint and Prototypes}

At this stage, the development of the prototypes was carried out according to the modules already established, with Fig. 3, Fig. 4, Fig. 5, Fig. 6, Fig. 7 and Fig. 8.

For each Sprint, five increments were developed, which are the sum of all the elements developed during the Sprint:

Increment 1 (Login Module): Here is developed the interface that allows access to the platform, entering the respective credentials, as shown in Fig. 3.

Increment 2 (Registration Module): Fig. 4 shows us this module, which allows us to register applicants so they can take the admission test.

TABLE I. BACKLOG CREATION

\begin{tabular}{|l|l|}
\hline User History & Priority \\
\hline $\begin{array}{l}\text { As a user I want to enter the credentials to have access to the } \\
\text { admission test platform. }\end{array}$ & 3 \\
\hline $\begin{array}{l}\text { As an academic assistant I want to consult, update and register } \\
\text { applicants so that they can take their entrance exam. }\end{array}$ & 1 \\
\hline $\begin{array}{l}\text { As an academic assistant I want to record the questions and } \\
\text { answers of the exam so that applicants can take the exam. }\end{array}$ & 1 \\
\hline $\begin{array}{l}\text { As an applicant I want to take the entrance exam in order to get } \\
\text { into the university. }\end{array}$ & 2 \\
\hline $\begin{array}{l}\text { As an academic assistant I want to generate the results of the } \\
\text { entrance exam to publish the entrants. }\end{array}$ & 2 \\
\hline $\begin{array}{l}\text { As an academic assistant I want to generate the results of the } \\
\text { entrance exam to publish the entrants. }\end{array}$ & 3 \\
\hline $\begin{array}{l}\text { As a teacher I want to read the questions on the entrance exam } \\
\text { to guide the student in case he or she does not understand the } \\
\text { question. }\end{array}$ & 3 \\
\hline $\begin{array}{l}\text { As an academic assistant I want to see in graphic format the } \\
\text { results of the exam in order to make an analysis of the } \\
\text { performance of the applicants. }\end{array}$ & $\begin{array}{l}\text { As an academic assistant I want to visualize if any of the } \\
\text { applicants have any limitations or disabilities so that I can } \\
\text { assign them to a different type of exam. }\end{array}$ \\
\hline
\end{tabular}

TABLE II. BACKLOG CREATION

\begin{tabular}{|l|l|}
\hline User History & Priority \\
\hline Admission test page for blind people. & 14 weeks \\
\hline Access Module. & 2 weeks \\
\hline Registration Module. & 2 weeks \\
\hline Examination Preparation Module. & 4 weeks \\
\hline Admission Test Module. & 4 weeks \\
\hline Results Module. & 2 weeks \\
\hline
\end{tabular}




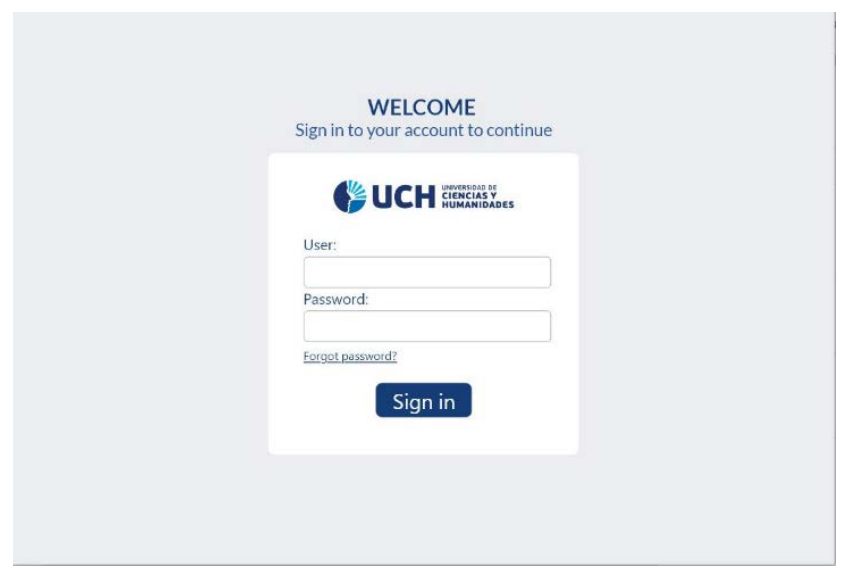

Fig. 3. Login Screen.

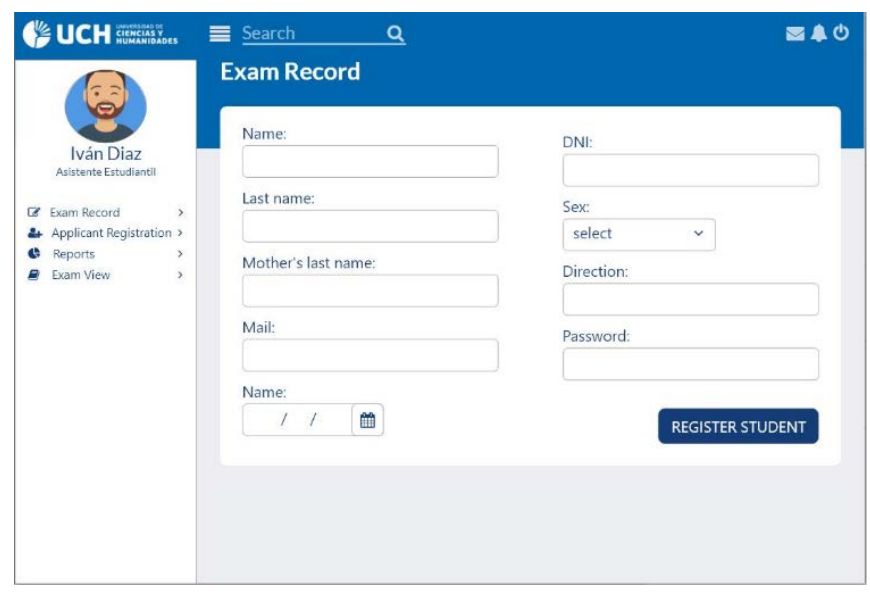

Fig. 4. The Student Registration Screen.

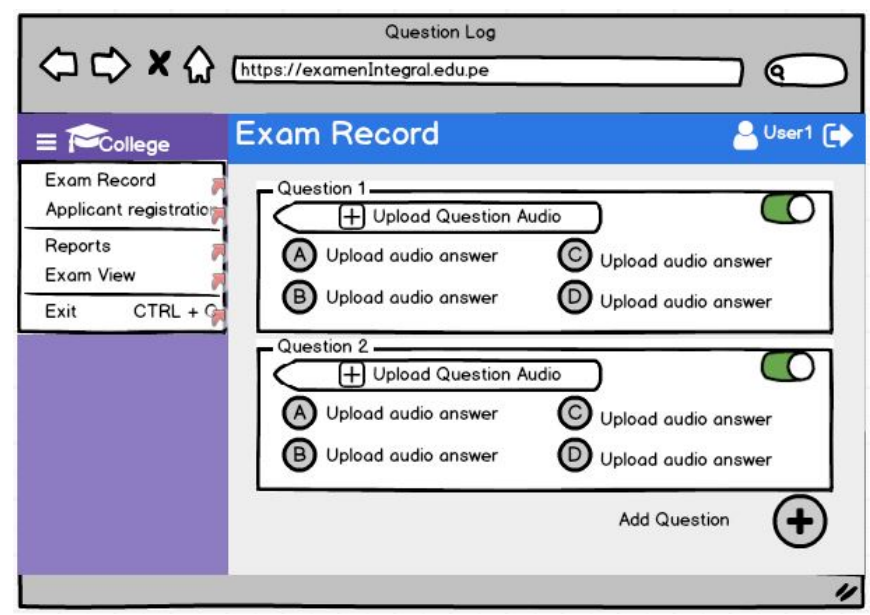

Fig. 5. The Question Registration Screen.

Increment 3 (Admission Test Preparation Module): This increment allows us to record the audios of the admission test questions and answers, as shown in Fig. 5.

Increment 4 (Admission Test Module): In this increment the student can play the audios of the admission test questions and answers, as shown in Fig. 6.
Increment 5 Increment 5 (Results Module): The module allows us to see two options: in the first one the applicant can know what his results were, as shown in Fig. 7; in the second one, the university staff can elaborate different reports on the results of all the applicants, as exemplified in Fig. 8.

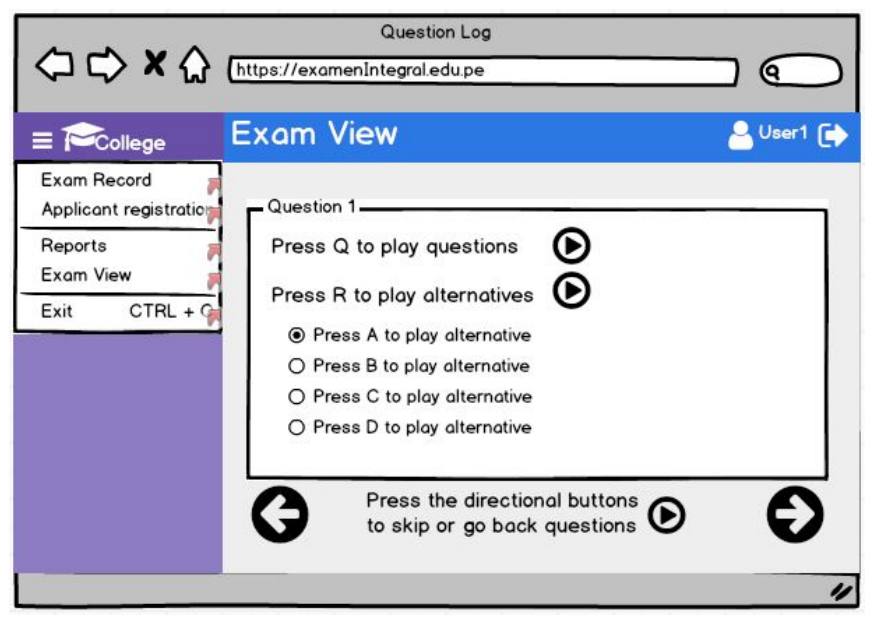

Fig. 6. The Admission Test Screen.

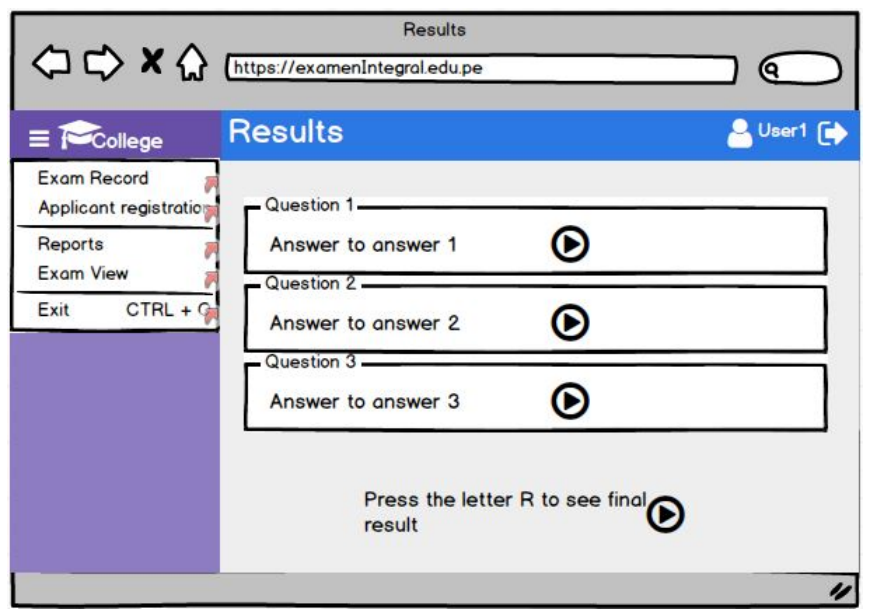

Fig. 7. Admission Test Results Screen.

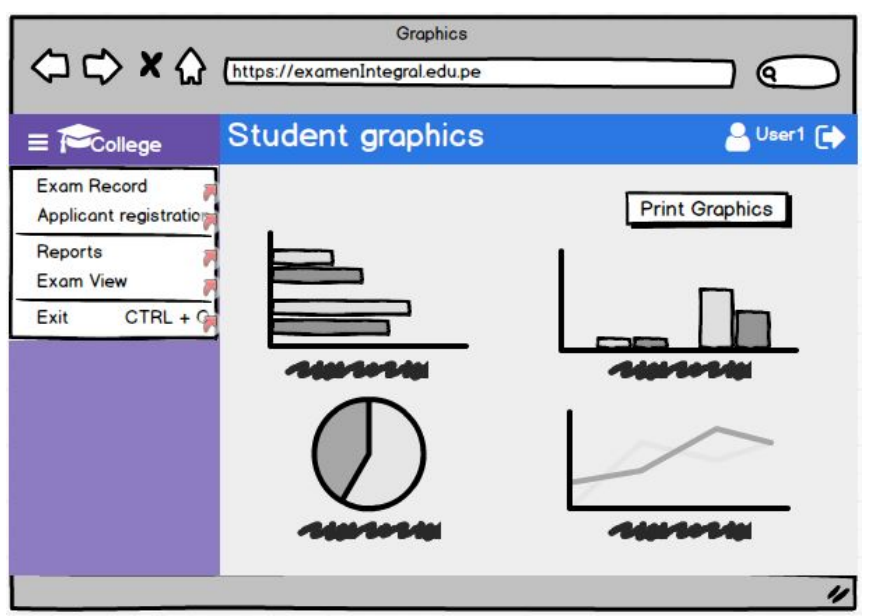

Fig. 8. Admission Test Graphics Screen. 


\section{E. Review of the Sprint}

The development team is responsible for reviewing the Sprint when it is finished, with an estimated time of three hours maximum. One of the team evaluates that each user history is fulfilled and applies changes if necessary. The team explains the development of each module and mentions each problem that arose during the development and the solution that was applied.

\section{F. Retrospective of the Sprint}

For the retrospective, the scrum team evaluates the finished sprint and the techniques that were used during its development. Both the programming language PHP, the database manager MySQL and the prototyping tools Balsamiq and Adobe are evaluated. Members suggest new methods and solutions for the improvement of the next Sprint.

\section{RESUlts AND DisCUSSIONS}

\section{A. About the Case Study}

The design and development of this case study resulted in the creation of the prototype of the web application for the admission exam for blind people, which has the purpose and objective of showing the correct function, interaction and comfort of the users, ensuring its operation and functionality. A result is presented to provide a solution to the lack of software tools for people with disabilities, thus achieving a step towards integration into society, thus improving the quality of life of this population.

The Balsamiq tool was of great importance, since with it the prototypes of the web application were made, being easy to use and to adapt for the designer; demonstrating its great similarity to a web page. By having some basic options on buttons, grouping and positioning of various components, it allows agility and changes quickly [18]. In the same way, it allowed an easy adaptation when making designs in Adobe $\mathrm{XD}$.

In a comparison with other articles with reference to the applications for admission tests, it was observed that they offer adequate learning environments, tests and feedback, improving the knowledge and the self-evaluation process [19], being a benefit for the student; however, applications like these are not designed or destined to people with visual limitations, because of the visual tools that are used and not sound tools like recordings or texture tools like the friar, being these characteristics clear differences between our prototype and other similar applications. And this can be observed in the record of questions and alternatives Fig. 5, in which the questions and alternatives are entered in audios for people who are heard by the applicants with visual limitations or blind people. The result is a test in which the questions and alternatives can be heard without the need for someone to read them to them, improving their performance at the time of taking the test; the model of the test is shown in Fig. 6. It will consist of audios that will be played at the time of passing the questions, which will be played automatically, indicating the question and the alternatives, as well as the buttons to be pressed to select the alternative. It is worth mentioning that the keyboard will have Braille stickers so that the student can distinguish the letters on the keyboard.

\section{B. About the Methodology}

Making a comparison with other articles, the development of the application was made taking into account points of the soft systems methodology, which is shown as an approach to address problematic and disordered situations of all kinds focusing the development [20]; the soft systems methodology compared to other methodologies, such as Design Thinking, has the advantage of analyzing with a holistic vision under the systemic thinking, which allowed articulating all the involved of the problem; on the other hand, Design Thinking does not articulate all the parts. In the same way, for the development of the case study, the steps specified in the Scrum methodology were followed, focusing more on the deliverables. Because having a single model as a waterfall or prototype for development is not enough for the requirements of the product and, therefore, agile development is more useful for the development of customized products [21].

The use of the Scrum methodology allowed the development team and the end users to work with a better productivity, through continuous revisions during each Sprint and with the feedback that helps to solve problems at the time of development. In addition, he demonstrated many advantages of using this development methodology, is that it largely drives collaborative work, accept the changes within each Sprint completed and make software deliveries gradually, until the final product. Similarly, the flexibility it had for the selection of sprints, makes it possible to work in different ways development projects [22].

\section{CONCLUSIONS AND FUTURE WORK}

The prototype web application helps blind people to take an entrance exam with more autonomy. The application will allow the inclusion of visually impaired people towards an admission test, making it easy to get into any college. The use of the programming language PHP and the database manager MySQL, being free software, reduces the investment cost for the development of the web application. It is recommended that in the future the web application be implemented in Peruvian universities, since it would be a great step towards inclusion for blind people. Similarly, not only use it in the admission exam, but also in the exams they may take throughout their career.

\section{REFERENCES}

[1] D. Rocha, V. Carvalho, E. Oliveira, J. Gonc alves, and F. Azevedo, "Myeyes-automatic combination system ofclothing parts to blind people: First insights,” pp. 1-5, 2017.

[2] M. Zhou, W. Li, and B. Zhou, “An iot system designfor blind,” pp. 9092, 2017.

[3] INEI, "En el Perú 1 millón 575 mil personas presentan algún tipo de discapacidad,” Extraído de: https://www.inei.gob.pe/prensa/noticias/enel-peru-1-millon-575-mil-personas-presentan-alg/, 2013.

[4] Defensoria del Pueblo, "Deficiencias en atención a postulantes con discapacidad en examen de admisióna una puno,” 2019.

[5] R. P. Machado, D. Conforto, and L. Santarosa, "Perception for cooperation: Case study in web text editorsfrom the perspective of blind users," pp. 1-6, 2016.

[6] N. A. Miftahul Huda and I. Sembiring, "The use of softsystems methodology to resolve hoax news problems indonesia," pp. 65-68, 2018. 
[7] F. Hayat, A. U. Rehman, K. S. Arif, K. Wahab, and M. Abbas, “The influence of agile methodology (scrum) on software project management,” pp. 145-149, 2019.

[8] B. L. Romano and A. Delgado Da Silva, "Projectmanagement using the scrum agile Method: A case study within a small enterprise,” pp. 774776, 2015.

[9] HEURTEL, Olivier. PHP 5.6: desarrollar un sitio web dinámico e interactivo. Ediciones ENI, 2015.

[10] J. S. Aleman Fierro, "Diseñoo de una metodología para cluster de base de datos oracle mysql de alta disponibilidad, con un demo de aplicación en servidores linux.”, B. S. thesis, Quito: UCE, 2016.

[11] C. L. Loor, J. O. Estrada, N. Q. Sanmartin, and G. M.Guacho, "Prototipo de una aplicación móvil para el diseño de curva de carreteras,” vol. 3,no.1, pp. 836-847, 2019.

[12] M. R. Z. NAVA et al., “Análisis de herramientas para el diseño de mockups.," 2017.

[13] A. Aldaz and P. Juan, "Sistema electrónico para la enseñanza del lenguaje braille a personas invidentes,”2016.

[14] M. V. M. Carrasco, "La discapacidad en el Perú y adaptaciones de accesibilidad de espacios e infraestructura en centros educativos inclusivos,” Educación, vol. 24, no. 1, pp. 35-45, 2018.

[15] M. D. l. A. Terrazas Garcia, “Accesibilidad a la información de usuarios con discapacidad visual a la biblioteca central "pedro zulen” de la unmsm,” 2018.
[16] V. A. Corzo, “Reflexión crítica de la educación inclusiva,” 2020.

[17] S. C. Simplican, G. Leader, J. Kosciulek, and M. Leahy, "Defining social inclusion of people with intellectualand developmental disabilities: An ecological model ofsocial networks and community participation,” Researchin developmental disabilities, vol. 38, pp. 18-29, 2015.

[18] A. Delgado and J. Sosa, "Mobile application design ofgeolocation to collect solid waste: A case study in lima,peru,” pp. 1-4, 2019.

[19] A. Robu, I. Filip, R. Robu, I. Szeidert and C. Vasar, "Online Platform for University Admission," 2018 9th International Conference on Information, Intelligence, Systems and Applications (IISA), Zakynthos, Greece, 2018, pp. 1-5, doi: 10.1109/IISA.2018.8633616.

[20] P. Checkland and J. Poulter, "Soft systems methodology," in Systems Approaches to Making Change: APractical Guide, Springer, 2020, pp. 201-253.

[21] A. Srivastava, S. Bhardwaj, and S. Saraswat, "Scrummodel for agile methodology," in 2017 International Conference on Computing, Communication and Automation (ICCCA), IEEE, 2017, pp. 864-869.

[22] A. Srivastava, S. Bhardwaj, and S. Saraswat" Scrummodel for agile methodology,” pp. 864-869, May 2017.DOI: 10.1109/CCAA.2017.8229928 